\title{
Associações de técnicas para recobrimento radicular
}

\author{
Associations of techniques for root covering \\ Asociaciones de técnicas para el recubrimiento de raíces
}

Larissa Meneghel $^{1 *}$, Daniel Damiani Zamprogno', Juliê Ferrari Ambrozio ${ }^{1}$, Macrina Reis y D'la Guardia $^{1}$, Mariana Ferreira Foligno ${ }^{1}$, Suzane Kamilly Patrício Costa ${ }^{2}$, Brenda Lacerda da Silva Satler ${ }^{1}$.

\section{RESUMO}

Objetivo: Analisar as técnicas de tratamento para recessões gengivais e suas associações. Revisão bibliográfica: A recessão gengival é caracterizada pela perda ou diminuição do tecido da gengiva, resultando na perda de inserção e em uma posição mais inferior da margem gengival livre. $O$ tratamento das recessões pode ser realizado através de enxertos de tecido conjuntivo e tem como padrão ouro o enxerto de tecido conjuntivo subepitelial, porém com desvantagem quanto a necessidade de duas áreas cirúrgicas. Existem ainda diversas técnicas que, quando associadas, podem melhorar o prognóstico pós cirúrgico, entre elas a matriz de derme acelular e proteínas da matriz de esmalte. Podem ser usadas, ainda, as técnicas de retalho posicionado coronalmente, retalho posicionado lateralmente e a técnica de matriz de colágeno xenogênico, que pode tratar múltiplas recessões gengivais, causar menos dor, menor tempo operatório e necessita de uma única área de cirúrgica. Considerações finais: Os procedimentos de recobrimento radicular são de grande importância no tratamento das recessões gengivais. Contudo, independente da técnica escolhida, o tratamento deve ser feito de forma individualizada, levando em conta as características e necessidades de cada paciente.

Palavras-chave: Retração gengival, Tecido conjuntivo, Transplante.

\begin{abstract}
Objective: Analyze treatment techniques for gingival recessions and their associations. Bibliographic review: Gingival recession is characterized by the loss or shrinkage of gingival tissue, resulting in attachment loss and a lower position of the free gingival margin. The treatment of recessions can be performed using connective tissue grafts and the subepithelial connective tissue graft is the gold standard, but with a disadvantage regarding the need for two surgical areas. There are also several techniques that, when combined, can improve the post-surgical prognosis, including the acellular dermis matrix and enamel matrix proteins. Coronally positioned flap, laterally positioned flap and xenogenic collagen matrix techniques can be used, which can treat multiple gingival recessions, cause less pain, less operative time and require a single surgical area. Final considerations: Root covering procedures are of great importance in the treatment of gingival recessions. However, regardless of the chosen technique, treatment must be done individually, taking into account the characteristics and needs of each patient.
\end{abstract}

Key words: Gingival recession, Connective tissue, Transplantation.

\section{RESUMEN}

Objetivo: Analizar las técnicas de tratamiento de las recesiones gingivales y sus asociaciones. Revisión bibliográfica: La recesión gingival se caracteriza por la pérdida o encogimiento del tejido gingival, lo que da

1 Universidade de Vila Velha (UVV), Vila Velha - ES. *E-mail: larissa.meneghelod@hotmail.com
${ }^{2}$ Universidade do Estado do Amazonas (UEA), Manaus - AM.

SUBMETIDO EM: 6/2021

ACEITO EM: 6/2021

PUBLICADO EM: 72021 
como resultado la pérdida de inserción y una posición más baja del margen gingival libre. El tratamiento de las recesiones se puede realizar mediante injertos de tejido conectivo y el injerto de tejido conectivo subepitelial es el estándar de oro, pero con una desventaja en cuanto a la necesidad de dos áreas quirúrgicas. También existen varias técnicas que, combinadas, pueden mejorar el pronóstico posquirúrgico, incluida la matriz de la dermis acelular y las proteínas de la matriz del esmalte. Se pueden utilizar técnicas de colgajo posicionado coronalmente, colgajo posicionado lateralmente y matriz de colágeno xenogénico, que pueden tratar múltiples recesiones gingivales, causar menos dolor, menos tiempo operatorio y requerir de una sola área quirúrgica. Consideraciones finales: Los procedimientos de recubrimiento radicular son de gran importancia en el tratamiento de las recesiones gingivales. Sin embargo, independientemente de la técnica elegida, el tratamiento debe realizarse de forma individual, teniendo en cuenta las características y necesidades de cada paciente.

Palabras clave: Recesión gingival, Tejido conectivo, Trasplante.

\section{INTRODUÇÃO}

A recessão gengival é caracterizada pela perda ou diminuição do tecido da gengiva, resultando na perda de inserção e em uma posição mais inferior da margem gengival livre. Apesar de se tratar um acometimento comum em todos os tipos populacionais, a prevalência e a gravidade da recessão gengival aumentam com a idade. Entre os fatores associados à etiologia da recessão, citam-se: a inflamação gengival causada pelo biofilme bacteriano, o trauma oclusal, o trauma causado pela escovação ou inserção alterada do freio labial. Outros fatores também podem estar associados como características anatômicas locais e individuais relacionadas ao posicionamento dentário, espessura da gengiva marginal, altura da faixa de mucosa ceratinizada e tecido ósseo subjacente (GÓMEZ AM, 2019).

Em 1985, Miller Jr propôs uma classificação para as recessões gengivais, considerando que o prognóstico do recobrimento radicular é influenciado pela posição da margem gengival em relação à junção mucogengival, pela perda de osso ou de gengiva interdental e pelo posicionamento dental, as lesões foram classificadas em Classe I, Classe II, Classe III e Classe IV (GOYAL L, 2019). Recentemente, foi proposta uma nova Classificação das Doenças e Condições Periodontais e Peri-implantares que classifica a recessão gengival em recessão tipo 1 (RT1), recessão tipo 2 (RT2) e recessão tipo 3 (RT3) (STEFFENS JP e MARCANTONIO RC, 2018).

Os procedimentos de recobrimento radicular são importantes no tratamento periodontal, à medida que têm o objetivo de corrigir as recessões gengivais com comprometimento estético, eliminar a sensibilidade radicular e reduzir o risco de desenvolvimento de lesões cariosas nas superfícies radiculares expostas. O prognóstico do recobrimento radicular nas Classes I e II é de 100\%, enquanto que para a Classe III não é possível recobrimento total e na Classe IV, por sua vez, não há previsibilidade de recobrimento radicular total (KINA JR, et al., 2015; CAMPO MV e HOYOS LM, 2015).

Dessa forma, o tratamento passou a obter resultados mais previsíveis quanto ao recobrimento gengival a partir da implementação de técnicas como a utilização do enxerto de tecido conjuntivo subepitelial, regeneração tecidual guiada, aloenxertos e xenoenxertos, uso da matriz dérmica acelular e matriz de colágeno porcino. A técnica de tecido conjuntivo subepitelial é a mais usada e, comumente, é associada a fatores que auxiliam na cicatrização, como a matriz de colágeno (CAMPO MV e HOYOS LM, 2015).

Também é frequentemente associada com outras técnicas de recobrimento radicular, como a técnica de reposicionamento coronal e a técnica de reposicionamento lateral, quando o objetivo é não só cobrir a raiz exposta, mas também ganhar tecido em espessura no local da recessão (AHMEDBEYLI C, 2018; SANTOS GP e QUEIROZ AG, 2017).

Assim, o objetivo deste trabalho é descrever e discutir as principais técnicas de enxerto gengival usadas para o procedimento radicular, a partir de uma revisão da produção científica atual. 


\section{REVISÃO BIBLIOGRÁFICA}

A recessão gengival é definida como a migração apical da margem gengival em relação à junção cementoesmalte, deixando a porção radicular exposta na cavidade oral. As recessões possuem etiologia multifatorial e esses fatores podem ser classificados em precipitantes e predisponentes, sendo que um fator isolado pode não ocasionar o desenvolvimento de uma recessão (CAMPO MV e HOYOS LM, 2015).

Os fatores precipitantes incluem hábitos adquiridos ou condições que a introduzem, como o excesso de força mecânica durante a escovação, posicionamento do dente no arco, doença periodontal, iatrogenias em tratamento periodontal e restaurador, e o trauma oclusal. Encaixada nos fatores precipitantes, a higiene oral desfavorável contribui para a recessão da gengiva, já que a placa bacteriana induz inflamação, podendo levar a perda da inserção. Também precipitante, o hábito excessivo de escovação pode ocasionar a condição, dependendo da força empregada, dureza da escova, frequência e duração da escovação, frequência de troca das escovas, bem como das técnicas de escovação e tipos de escovas dentais (JATI AS, et al., 2016; CHAN HL, 2015).

Os fatores predisponentes, por sua vez, compreendem aqueles que podem induzir maiores chances de recessão como a diminuição da espessura da crista óssea alveolar, deiscência e inserção do freio próximo a porção cervical da gengiva. Crê-se que as condições que podem causar deiscência ou defeito de fenestração aumentem o risco do desenvolvimento de recessão, visto que o osso alveolar suporta o tecido mole sobreposto. Tecidos gengivais e ósseos alveolares delgados (como no caso de dentes com raízes mais proeminentes), juntamente com fatores precipitantes, como inflamação e trauma, podem levar à recessão. Sem a presença desses fatores, a margem gengival com tecido fino ou falta de osso alveolar pode se manter intacta (JATI AS, et al., 2016; CHAN HL, 2015).

Existem ainda fatores que podem levar a alterações inflamatórias nas recessões resultantes, como trauma e irritação do tecido gengival local em decorrência da mastigação de tabaco e de piercing oral. Deve-se frisar que a raspagem e aplainamento radicular repetidos ou cirurgias periodontais em bolsas rasas também podem induzir perda de inserção, vista como recessão gengival. As consequências das recessões gengivais variam entre indivíduos, podendo-se destacar problemas estéticos, sensibilidade dentinária e maior possibilidade de cáries radiculares (CHAN HL, 2015).

O tratamento deve ser feito de forma individualizada, levando em conta a anatomia e posição do dente no arco, densidade óssea, quantidade de osso presente na região interproximal, a classificação da recessão gengival, característica gengival, bem como presença e quantidade de gengiva queratinizada em cada paciente. Todos esses fatores auxiliam no prognóstico e na previsibilidade da técnica a ser utilizada. É importante salientar, ainda, que a junção cemento-esmalte é usada como referência para a definição da recessão gengival bem como para auxiliar na escolha do tratamento (KINA JR, et al., 2015; CAMPO MV e HOYOS LM, 2015).

De acordo com os critérios propostos por Miller Jr, a recessão gengival pode ser classificada em: Classe I - Recessão de tecido marginal que não se estende à JMG, ausência de perda óssea e tecido mole interdentário; Classe II - Recessão do tecido marginal que se estende até ou para além da JMG, ausência de perda óssea e tecido mole interdentário; Classe III- Recessão de tecido marginal que se estende até ou para além da JMG, a perda óssea ou perda de tecidos moles interdentário é apical à junção cemento esmalte, porém coronal à extensão apical da recessão do tecido marginal; Classe IV - Recessão de tecido marginal que se estende até ou para além da JMG, a perda óssea interdentária estende-se até um nível apical em relação à extensão da recessão do tecido marginal (STEFFENS JP, 2018).

Steffens JP e Marcantonio RC (2018) propuseram, mais recentemente, uma nova classificação para as recessões gengivais, levando em conta sua extensão vertical. Dessa forma, elas foram divididas em três tipos, sendo a recessão tipo 1 (RT1) caracterizada pela ausência de perda de inserção interproximal, e a junção cemento esmalte não detectável clinicamente nas regiões mesial e distal. A recessão tipo 2 (RT2), por sua vez, não apresenta perda de inserção interproximal e a distância da junção cemento esmalte ao fundo do sulco ou bolsa é menor ou igual a perda de inserção vestibular. Já para a recessão tipo 3 (RT3), a nova 
classificação propõe que há perda de inserção interproximal e a distância da junção cemento esmalte até o fundo do sulco ou da bolsa é maior que a perda de inserção vestibular.

Assim, baseado na classificação da recessão, é possível estabelecer uma previsibilidade quanto ao tratamento. Dessa forma, nas classes I e II, por não apresentarem perda interdentária de osso ou tecido mole, é possível alcançar recobrimento total das recessões, e nas classes III e IV, é possível um recobrimento parcial (COSTA LM, et al., 2020).

Existem diversas formas de tratamento para as recessões gengivais, sendo os enxertos uma opção usada na substituição de defeitos de tecidos moles ao redor dos dentes. Dessa forma, os enxertos são importantes para devolver forma, função e estética para as regiões envolvidas. O Enxerto de Tecido Conjuntivo Subepitelial (ETCS) é uma excelente opção para recobrimento radicular (KARTHIKEYAN BV, et al., 2016).

O ETCS é considerado padrão-ouro para as recessões unitárias Classe I e ll de Miller e apresenta diversas vantagens (VALLE LA, et al., 2016). Entre essas vantagens, citam-se a estabilidade a curto e longo prazo, é econômico, fácil acesso anatômico, capacidade de reparo tanto da área doadora como receptora, maior cobertura da região radicular, semelhança com os tecidos adjacentes, maior suprimento sanguíneo, bem como amplia a quantidade de tecido queratinizado. O sucesso em longo prazo está relacionado com adequada fixação, íntimo contato com a área receptora e revascularização. Entretanto, algumas desvantagens do ETCS estão descritas na literatura, como a necessidade de dois sítios cirúrgicos, sendo um para remoção do enxerto e o segundo para recobrimento da recessão gengival, tempo clínico e possíveis transtornos no pós-operatório para o paciente (KARTHIKEYAN BV, et al., 2016; SANTOS GP e QUEIROZ $A G, 2017)$.

As principais áreas doadoras de ETCS são o palato na região entre os pré-molares e primeiro molar, regiões edêntulas e retromolar (SANTOS GP e QUEIROZ AG, 2017). Aroni MT, et al. (2016) realizaram um estudo que avaliou a cobertura das recessões gengivais de classe I e II de Miller tratadas com ETCS, Matriz de Derme Acelular (MDA) e Proteínas da Matriz de Esmalte (PME). O grupo que recebeu o ETCS foi associado à técnica de Retalho Posicionado Coronalmente (RPC) e o tecido epitelial foi removido do palato e levado para a área receptora, cobrindo a região da recessão. A conclusão, após análise dos resultados foi que o ETCS E MDA foram mais eficazes para o tratamento de recessões gengivais do que a PME.

O RPC é classificado como um enxerto pediculado e a técnica consiste no deslocamento vertical do tecido gengival, com a finalidade de recobrir a região da raiz que apresenta exposição. É considerado um procedimento simples e não necessita de dois sítios cirúrgicos, trazendo mais conforto ao paciente no pósoperatório. Contudo, antes de realizar a técnica é importante verificar a largura e espessura de gengiva na margem anterior do retalho a ser confeccionado, para obtenção de resultados clínicos satisfatórios, além de avaliar a quantidade de tecido queratinizado disponível para realizar as suturas e estabilizar o retalho em posição (SANTOS GP e QUEIROZ AG, 2017).

A associação das técnicas de ETCS e RPC para recobrimento radicular em pacientes com recessão gengival é feita colocando o tecido conjuntivo subepitelial abaixo do RPC, favorecendo a cor e espessura do tecido na cicatrização inicial. Os resultados alcançados podem oferecer mais estética e melhorar a função. Somado a isso, em longo prazo, o tecido pode ficar queratinizado (CAMPO MV e HOYOS LM, 2015).

O Retalho Posicionado Lateralmente (RPL) também é um enxerto pediculado e foi inicialmente sugerido por Grupe HE e Warren RF (1956), e posteriormente modificada por Grupe HE (1966), onde o sítio doador é representado pela gengiva adjacente ao sítio a ser retratado e é indicado nos casos de recessões gengivais (RG) que estejam restritas somente a um ou dois dentes (AHMEDBEYLI C, 2018).

A técnica original compreendia uma incisão gengival vertical em cada lado da recessão, uma incisão horizontal na base da fenda e posteriormente era feita uma incisão vertical que se estendia até a mucosa alveolar. $O$ retalho de espessura total era elevado, a parte apical dissecada em retalho dividido e o mesmo era posicionado lateralmente sobre a área da recessão (GOYAL L, 2019). 
Várias modificações nesse procedimento foram propostas e, hoje, a técnica consiste de uma incisão em forma de "V" desenhada em torno da recessão, permitindo o ajustamento eficiente das bordas. A área próxima à raiz deve ter espessura total para sustentar a nutrição dos vasos supraperiósticos para a raiz desnuda e 0 local da incisão relaxante lateral deve ser tratado mantendo-se o periósteo íntegro. A técnica de RPL é de fácil execução, por isso também muito utilizada, e tem vantagens por não precisar transplantar tecidos de outras regiões, além da característica de cor do retalho ser da mesma tonalidade, diminuindo as diferenças estéticas (LEE CT, et al., 2014).

Sabe-se que o ETCS é a técnica para recobrimento radicular mais frequentemente utilizada em função da previsibilidade de seus resultados, restabelecendo a estética e função dos tecidos gengivais. Dessa forma, Nelson SW (1987) propôs a combinação do enxerto de tecido conjuntivo com o retalho posicionado lateralmente. Quando associadas, essas técnicas permitem duplo suprimento sanguíneo que influencia positivamente os resultados, promovendo mimetização da mesma coloração dos tecidos adjacentes ao enxerto, sucesso terapêutico e recobrimento satisfatório (SAGARWAL C, et al., 2014).

Entre as vantagens da associação das técnicas do RPL ao ETCS, citam-se o tecido gengival do retalho adjacente de mesmo aspecto ser transferido para o sítio a ser tratado, possibilidade de bom resultado estético tendo maior chance de sobrevivência do enxerto e aumento de tecido queratinizado. O uso de ETCS também promove melhor estabilidade da margem gengival minimizando a contração durante o processo de reparo, contribuindo com a saúde dos tecidos periodontais (AHMEDBEYLI C, 2018).

Outra técnica para recobrimento radicular é a de matriz de colágeno xenogênico ( $M C X)$, a qual pode substituir enxertos de tecidos moles com a finalidade de aumentar a largura e espessura da banda de tecido queratinizado circundante de dentes e implantes para tratar RG múltiplas, além de estar associada a menos dor, menor tempo operatório e por não depender de área doadora. Diferente das recessões isoladas, as $R G$ múltiplas oferecem maior desafio para seu tratamento devido ao grande campo cirúrgico, fatores anatômicos e quantidade limitada de tecido conjuntivo na área doadora. Apesar do ETCS oferecer melhores resultados clínicos, esta técnica está associada a maior tempo operatório, dor e desconforto relacionado à área doadora na cobertura radicular no tratamento de múltiplas RG localizadas de classe I e II de Miller. Em adição, complicações trans e pós-operatórias podem ser causadas durante a remoção de enxerto (NAHAS R, et al., 2019; TONETTI MS, et al., 2018).

Diante de tais complicações, as matrizes de colágeno vieram como alternativa, possuindo outras vantagens, além das citadas, como não precisar de doadores humanos, não ter risco de transmissão de doenças humanas, ser regulamentada como um dispositivo médico e não como um transplante, e não possuir limites no tamanho do sítio cirúrgico. Além disso, a MCX é substituída pelo próprio tecido do hospedeiro com as características histológicas e funcionais desejadas. Quando adicionada a retalhos reposicionados coronalmente, ela fornece benefício em termos de espessura marginal do tecido mole em recessões isoladas em comparação com os retalhos coronais avançados isoladamente. Para cobrir recessões múltiplas adjacentes, tal associação resulta num menor tempo cirúrgico e de recuperação do paciente, comparando com o enxerto de tecido conjuntivo autólogo (TONETTI MS, et al., 2018).

\section{CONSIDERAÇÕES FINAIS}

A recessão gengival é um problema muito comum e os procedimentos de recobrimento radicular são de grande importância na terapia periodontal. Os enxertos são uma opção usada na substituição de defeitos de tecidos moles ao redor dos dentes, devolvendo forma, função e estética para as regiões envolvidas. Neste trabalho, observou-se que o ETCS é o padrão ouro em caso de recessões classe I e II de Miller, e pode ser associado a diferentes técnicas, como a RPC que oferece melhor estética, e também à RPL melhorando o prognóstico pós cirúrgico. Existem ainda outras técnicas que podem ser utilizadas como a MDA, PME, e a MCX que tem como principal vantagem a utilização de um único sítio cirúrgico. Contudo, independente da técnica escolhida, o tratamento das recessões deve ser feito de forma individualizada, levando em conta as características e necessidades de cada paciente. 


\section{REFERÊNCIAS}

1. AGARWAL C, et al. Abordagem modificada da técnica de retalho posicionado lateralmente de papilas duplas usando Alloderm® para cobertura radicular. Journal of Clinical and Diagnostic Research, 2014; 8: 25-27.

2. AHMEDBEYLI C. Laterally positioned flap along with acellular dermal matrix graft in the management of maxillary localized recessions. Clinical Oral Investigations, 2018; 23(2): 595-601.

3. ARONI MT, et al. Coverage of Miller class I and II gingival recessions treated with subepithelial connective tissue graft, acellular dermal matrix, and enamel matrix proteins. Pilot study. Revista de Odontologia da Universidade de São Paulo, 2016; 45(2): 78-84.

4. CAMPO MV, HOYOS LM. Factores associados al colgajo posicionado coronal del uno o dos dientes - Revisión de la literatura. Revista Faculdad de Odontología Universidade de Antioquia, 2015; 26(2): 368-397.

5. CHAN HL, et al. Does Gingival Recession Require Surgical Treatment? Dental Clinics of North America, 2015; 59(4): 981-996.

6. COSTA LM, et al. Recobrimento radicular com enxerto de tecido conjuntivo e fibrina rica em plaquetas: uma revisão crítica. Arquivos em Odontologia, 2020; 56(12): 8.

7. GÓMEZ, AM. Recessão gengival e Tratamento ortodôntico. Dissertação (Mestrado Integrado em Medicina Dentaria). Universidade Fernando Pessoa, Porto, 2019, 32 p.

8. CLAUDINO GF, et al. Recobrimento radicular em recessão gengival classe III de Miller utilizando o retalho deslocado lateralmente: relato de caso. Revista de Odontologia Contemporânea, 2018; 2(1): 89-96.

9. GOYAL L. Free Gingival Graft as a Single Step Procedure for Treatment of Mandibular Miller Class I and II Recession Defects. World journal of plastic surgery, 2019; 8(1): 12-17.

10. GRUPE HE, WARREN R. Repair of gingival defects by sliding flap operation. The Journal of Periodontology, 956;27:92-5.

11. JATI AS, et al. Recessão gengival: suas causas e tipos, e a importância do tratamento ortodôntico. Dental Press Journal of Orthotontics, 2016; 21(3):368-397.

12. KINA JR, et al. Tratamento de recessão gengival unitária.Archives of health investigation, 2015; 4(6): 25-30.

13. KARTHIKEYAN BV, et al. The versatile subepithelial connective tissue graft: a literature update. Revista General Dentistry, 2016; 64(6): 28-33.

14. LEE CT, et al. Cobertura da raiz com um retalho posicionado lateralmente modificado combinado com um enxerto de tecido conjuntivo subepitelial em recessão avançada. Journal of Periodontal \& Implant Science, 2014; 44: 300-306.

15. MILLER JR PD. A classification of marginal tissue recession. International journal of periodontics and restorative dentistry, $1985 ; 5(2): 8-13$.

16. NAHAS R, et al. Treatment of multiple recessions with collagen matrix versus connective tissue: a randomized clinical trial. Brazilian Oral Research, 2019; 33: 123.

17. NELSON SW. The subpedicle connective tissue graft. A bilaminar reconstructive procedure for the coverage of denuded root surfaces. Journal of Periodontology, 1987; 58: 95-102.

18. SANTOS GP, QUEIROZ AG. Vantagens do retalho posicionado coronalmente associado ao enxerto de tecido conjuntivo subepitelial e a proteína derivada da matriz de esmalte no recobrimento radicular, Revista Pró-univerSUS, 2017; 8(1): 69-71.

19. STEFFENS JP. Classificação das Doenças e Condições Periodontais e Peri implantares 2018: guia Prático e PontosChave. Revista de Odontologia da UNESP, 2018; 47(4): 189-197.

20. STEFFENS JP, MARCANTONIO RC. Classificação das doenças Periodontais e Peri-implantares 2018: guia prático e pontos-chave. Revista de Odontologia da Universidade Estadual de São Paulo, 2018; 44(4): 189-197.

21. TASHIRO EM. Enxertos autógeno, alógeno e xenógeno no tratamento de defeitos periimplantares. Monografia (especialização em implantodontia) - Faculdade Sete Lagoas, São Paulo, 2020; 30p.

22. TONETTI MS, et al. Xenogenic collagen matrix or autologous connective tissue graft as adjunct to coronally advanced flaps for coverage of multiple adjacent gingival recession: Randomized trial assessing non-inferiority in root coverage and superiority in oral health-related quality of life. Journal of Clinical Periodontology, 2017; 45: 78-88.

23. VALLE LA, et al. Uma revisão diferenciada sobre o enxerto de tecido conjuntivo subepitelia. Revista ImplantNewsPerio, 2016; 1(17): 1403-1409. 